\title{
Narrative review of telemedicine consultation in medical practice
}

This article was published in the following Dove Press journal:

Patient Preference and Adherence

13 January 2015

Number of times this article has been viewed

\section{Alessandro Di Cerbo ${ }^{1,2}$ Julio Cesar Morales- \\ Medina $^{3}$ \\ Beniamino Palmieri ${ }^{1,2}$ \\ Tommaso lannitti ${ }^{4}$}

'Poliambulatorio del Secondo Parere, ${ }^{2}$ Department of General Surgery and Surgical Specialties, Surgical Clinic, University of Modena and Reggio Emilia Medical School, Modena, Italy; ${ }^{3}$ Centro de Investigación en Reproducción Animal, CINVESTAV, Universidad Autónoma de Tlaxcala, Tlaxcala de Xicohténcatl, Mexico; ${ }^{4}$ Department of Neuroscience, Sheffield Institute for Translational Neuroscience (SITraN), University of Sheffield, Sheffield, UK
Correspondence: Tommaso lannitti Sheffield Institute for Translational Neuroscience (SITraN), University of Sheffield, 385a Glossop Road, Sheffield, SIO 2HQ, UK

Tel +44 752147 I447

Email tommaso.iannitti@gmail.com
Background: The use of telemedicine has grown across several medical fields, due to the increasing number of "e-patients".

Objective: This narrative review gives an overview of the growing use of telemedicine in different medical specialties, showing how its use can improve medical care.

Methods: A PubMed/Medline, Embase, Web of Science, and Scopus search was performed using the following keywords: telemedicine, teleconsultation, telehealth, e-health, and e-medicine. Selected papers from 1996 to 2014 were chosen on the basis of their content (quality and novelty).

Results: Telemedicine has already been applied to different areas of medical practice, and it is as effective as face-to-face medical care, at least for the diagnosis and treatment of some pathological conditions.

Conclusion: Telemedicine is time- and cost-effective for both patients and health care professionals, encouraging its use on a larger scale. Telemedicine provides specialist medical care to patients who have poor access to hospitals, and ensures continuity of care and optimal use of available health resources. The use of telemedicine opens new perspectives for patients seeking a medical second opinion for their pathology, since they can have remote access to medical resources that would otherwise require enormous costs and time.

Keywords: telemedicine, health care, patient

\section{Background}

Nowadays, the importance of telemedicine consultation has grown across several medical fields, and patients are a virtual entity dressed with "binary clothes". In 2005, $83 \%$ of Dutch citizens, aged between 12 and 75 years, had access to the Internet, and $47 \%$ of them used the web to obtain medical information. ${ }^{1}$ Furthermore, a 2009 report showed that $74 \%$ of all US adults used the Internet, and $61 \%$ used this technology to seek medical information. ${ }^{2}$ Given the availability of the Internet in numerous countries, medical science and practice have arranged new strategies to cope with the patient's needs, such as telemedicine, as showed by a study dating back to the 1970 s with the aim of improving the patient's care and efficacy of diagnostic and therapeutic treatments in remote hospitals. ${ }^{3}$ Telemedicine can be defined as the use of electronic means to transfer medical data from one place to another. ${ }^{4}$ At advanced levels, it may include the use of telecommunication facilities such as teleconferencing, while at a basic level it may include medical record keeping, data processing, and phone or email consultation. ${ }^{5}$ Telemedicine is mostly helpful in reducing the time needed to consult a specialist in underserved areas with small populations or densely populated areas lacking in resources. For example, in sub-Saharan Africa, on average, there are fewer than ten medical doctors per 100,000 people and 14 countries do not have radiologists. ${ }^{6}$ 
This area could benefit from the use of telemedicine in basic medical care, as well as teleradiology. This review gives an overview of the growing use of the telemedicine approach in different medical fields, underlying its importance as a valuable tool for the diagnosis and treatment of several pathological conditions.

\section{Review search criteria and aim}

A PubMed/Medline, Embase, Web of Science, and Scopus search was performed using the following keywords: telemedicine, teleconsultation, telehealth, e-health, and e-medicine. Selected papers from 1996 to 2014 were chosen on the basis of their content (quality and novelty). In this review, after a second screening, we included the ten areas of medicine that used the telemedicine approach more frequently, ie, psychiatry, cardiology, dermatology, surgery, ophthalmology, genetics, oncology, gastroenterology, dentistry, and geriatrics. Before the second screening, we retrieved 3,973 articles, and after the second screening, we included 56 articles in addition to some reviews regarding the telemedicine area. At least two reviewers independently assessed the retrieved studies for inclusion (ADC, JCMM, and TI). If an agreement could not be reached, a further reviewer arbitrated (BP). This review endeavors to list different applications of telemedicine in different medical specialties. A summary of our findings is provided in Table 1 .

\section{Telemedicine applications in different medical specialties Psychiatry and neurology}

Numerous studies have used different forms of telemedicine to treat, diagnose, and monitor mental health issues, and have been previously reviewed. ${ }^{7,8}$ For example, Bramanti et al analyzed the optimal location of territorial telemedicine spots near to general practitioner clinics for a more reliable teleneurology service. They allowed the use of telemedicine intervention by means of a geographical information system to several patients affected by multiple sclerosis and Alzheimer's disease. This strategy improved the patients' and their caregivers' quality of life, providing at the same time a continuity of care. ${ }^{9}$ In a further study, between 2004 and 2007, referral patterns to the Swinfen Charitable Trust (UK) from the Middle East (283 referrals from Iraq, Afghanistan, Pakistan, and Kuwait) and from the rest of the developing world (500 referrals) were compared. ${ }^{10}$ The median time required by the specialist to reply to the 283 referrals was 1 day. A significant difference, in terms of specialty referrals between the Middle East and the rest of the world, was observed, with a higher referral rate observed in obstetrics ( $18 \%$ of Middle Eastern referrals versus $6 \%$ of referrals from the rest of the world). In 20 out of 27 neurology referrals from Middle Eastern countries, the neurologist was reasonably confident about the diagnosis. The need for referrals using telecommunications technology also concerns clinical practitioners who seek an adequate training in specific medical issues, such as specific cognitive behavioral therapy for obsessive-compulsive disorder (OCD). ${ }^{11}$ Vogel et al reported the use of videoconference- and cell phone-based cognitive behavioral therapy in six patients with a variety of OCDs. Four out of six patients improved considerably and no longer met diagnostic criteria for OCD. As far as treatment of post-traumatic stress disorder is concerned, three separate studies indicated that videoconferencing is considered as successful as face-to-face therapy. Moreover, patients were satisfied with videoconferencing with respect to the discomfort of talking in person about painful past events. ${ }^{12-14}$ In subjects who suffer from depression-related disorders, four different studies involving more than 800 patients showed that videoconferencing was equal to faceto-face monitoring, and most notably there was an increase in adherence to the appointments and medication treatment, increased satisfaction, and reduced costs. ${ }^{15-18}$ In Denmark, two pilot studies involving a total of 91 patients used teleconferencing to diagnose and assess potential psychiatric disorders in asylum seekers, refugees, and migrants. ${ }^{19,20}$ Seventy-five patients completed a retrospective questionnaire survey at the end of treatment, reporting a high level of acceptance and satisfaction, as well as willingness to use teleconferencing again or recommend it to others. In summary, in the field of neurology, telemedicine can be effectively used for the diagnosis and treatment of at least some neurological conditions.

\section{Cardiology}

Telecardiology is a highly developed medical discipline involving almost every aspect of cardiology, including acute coronary syndromes, arrhythmias, congestive heart failure, and sudden cardiac arrest. ${ }^{21}$ Recently, an Italian project called TELEMedicina Ai piccoli COmuni lombardi (TELEMACO) provided home-based telemanagement services for patients with chronic heart failure and chronic obstructive pulmonary disease in selected territories with socioeconomic and infrastructural difficulties within rural areas of the Lombardy region. As a result, second-opinion teleconsultations in cardiology (4,830), dermatology (51), and diabetology (44), 
as well as teleconsultations in digital images concerning cases of traumatic brain injury (79) and stroke (68), were carried out with a substantial cost decrease. ${ }^{22}$ In India, 18 out of 102 pediatric consultations between a tertiary care cardiac center and a remote rural hospital received successful cardiac surgery following telediagnosis. ${ }^{23}$ Teleconsultations were also particularly useful for measuring changes in highrisk subjects' lifestyles and reducing the risk of coronary disease,${ }^{24}$ and in reducing systolic blood pressure and total cholesterol levels. ${ }^{25}$ In the UK, remote fetal echocardiograms confirmed telemedicine usefulness to diagnose congenital heart disease, ${ }^{26}$ and a pediatric telecardiology service was compared with the conventional service to evaluate patients' costs and outcomes. ${ }^{27}$ In the latter study, cardiologists, district clinicians, and families perceived telecardiology as a reliable and efficient tool. In the Netherlands, 214 patients affected by chronic heart failure received a home TV channel and were teleguided by a medical service center. ${ }^{28}$ In Italy, at the pediatric cardiology unit of Azienda Ospedaliera Brotzu (Cagliari), a system based on the transmission of two simultaneous video streams was used to survey a small group of neonatal cases with suspected cardiopathies. ${ }^{29}$ In Switzerland, 191 out of 194 children received a correct diagnosis of cardiovascular disease by an experienced sonographer in a remote hospital. ${ }^{30}$ These echocardiograms were transmitted to a distant tertiary care pediatric cardiology center by a telemedicine link across three Integrated Services Digital Network (ISDN) lines. ${ }^{31}$ Moreover, echocardiography-telemedicine efficacy was assessed in emergency conditions, in particular after regular working hours using a laptop computer. ${ }^{32}$ In the Netherlands, subjects with familial hypercholesterolemia were monitored to perform changes in their lifestyle habits, and were assigned either to a web-based lifestyle advice and personal counseling or to usual therapy for 12 months. At the end of the study, there were no differences in markers of risk associated with the disease. ${ }^{33}$ In summary, evidence supports the use of telecardiology as a reliable and cost-effective tool in terms of risk reduction, when used for diagnostic purposes, if compared with long-term face-to-face monitoring.

\section{Surgery}

Telesurgery can be defined as surgery performed by a surgeon who is not present in the same physical location of the patient. In 2003, in the first Italian telesurgery project, named RESPECT (REte SPECialistica per il Trauma), seven peripheral hospitals of the Messina area were connected to the Neurosurgery Department of the University of Messina. ${ }^{34}$ A population of 684,703 people was monitored through a high-technology "hub-and-spoke" network (hub = university; spoke $=$ connected hospitals). On average, neurosurgical consultation time was greatly reduced from 160 to 38 minutes. Therefore, telemedicine can be used to greatly reduce consultation time in the field of surgery. Telesurgery has also found applications for remote control of robotic computerenhanced manipulators to facilitate certain operations requiring fine-tissue laparoscopic manipulation ${ }^{35,36}$ such as radical prostatectomy, pyeloplasty, and Heller myotomy. ${ }^{37-44}$ In 1997, the first intercontinental telelaparoscopic adrenalectomy was performed between the US and Austria. ${ }^{45}$ Furthermore, in 2007, the Centre for Minimal Access Surgery at McMaster University used broadband Internet and telecommunication systems to provide distance training and mentoring to community surgeons living in remote northern communities in Canada. ${ }^{46}$ Another fascinating and futuristic aspect of telesurgery is the possibility to perform space operations. Several prototype systems have been created worldwide with the objective of facilitating telesurgery in space, ie, robot-assisted microsurgery (USA), the M7 robot (USA), the KineMedic and the most recent MiroSurge robots (Germany), and the Array of Robots Augmenting the KiNematics of Endoluminal Surgery (ARAKNES) project (Italy). ${ }^{47}$ These technologies enable physicians to perform surgical procedures with the aid of robotic systems, as shown by Sterbis et $\mathrm{al}^{48}$ as well as Haidegger et al. ${ }^{47}$ Therefore, telesurgery allows a reduction in consultation time, training, and mentoring among different geographic areas without the expensive mobilization of experts.

\section{Ophthalmology}

Several studies have applied telecommunication technology to deliver ophthalmology services at a distance. For instance, the use of a sophisticated digital retinal camera was used for a diagnostic screening for cytomegalovirus (CMV) retinitis among human immunodeficiency virus (HIV) patients in northern Thailand. ${ }^{49}$ In this study, between 2008 and 2009, 182 eyes from 94 patients affected by HIV were photographed and electronically graded for signs of CMV retinitis by three experts. Remote-grading results were then compared with on-site patient examination by local expert ophthalmologists. Detection of CMV retinitis by remote experts had a sensitivity of $88.8 \%-91.0 \%$ and a specificity of $84.9 \%-88.2 \%$ when compared with the gold standard - indirect ophthalmoscopy. Based on this evidence, telemedicine proved to be effective for HIV diagnosis when the number of patients exceeds the possibility of local eye care providers. Furthermore, telemedicine is useful for speeding up the response to patients affected by macular disorders. The value of telemedicine in 


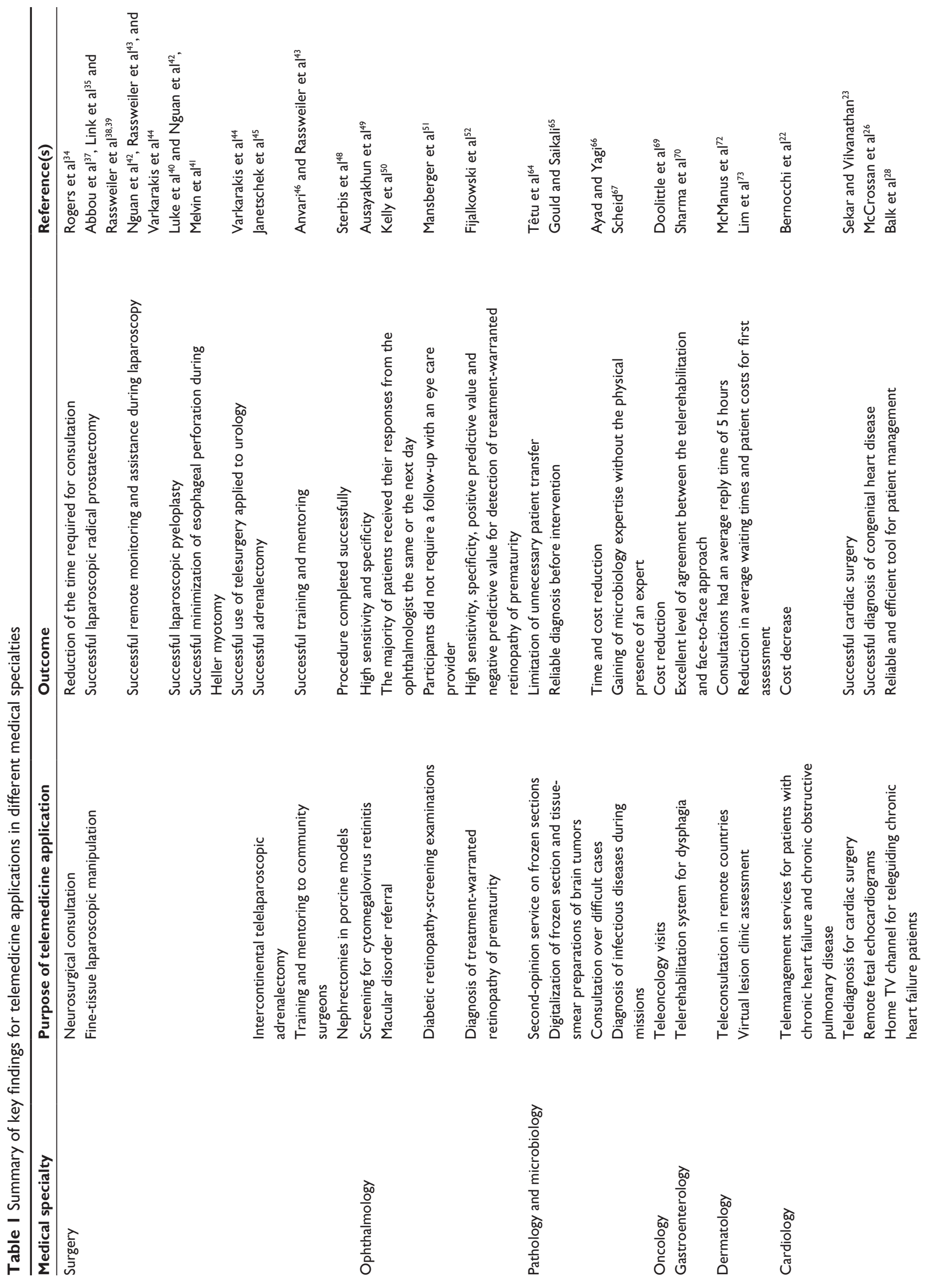



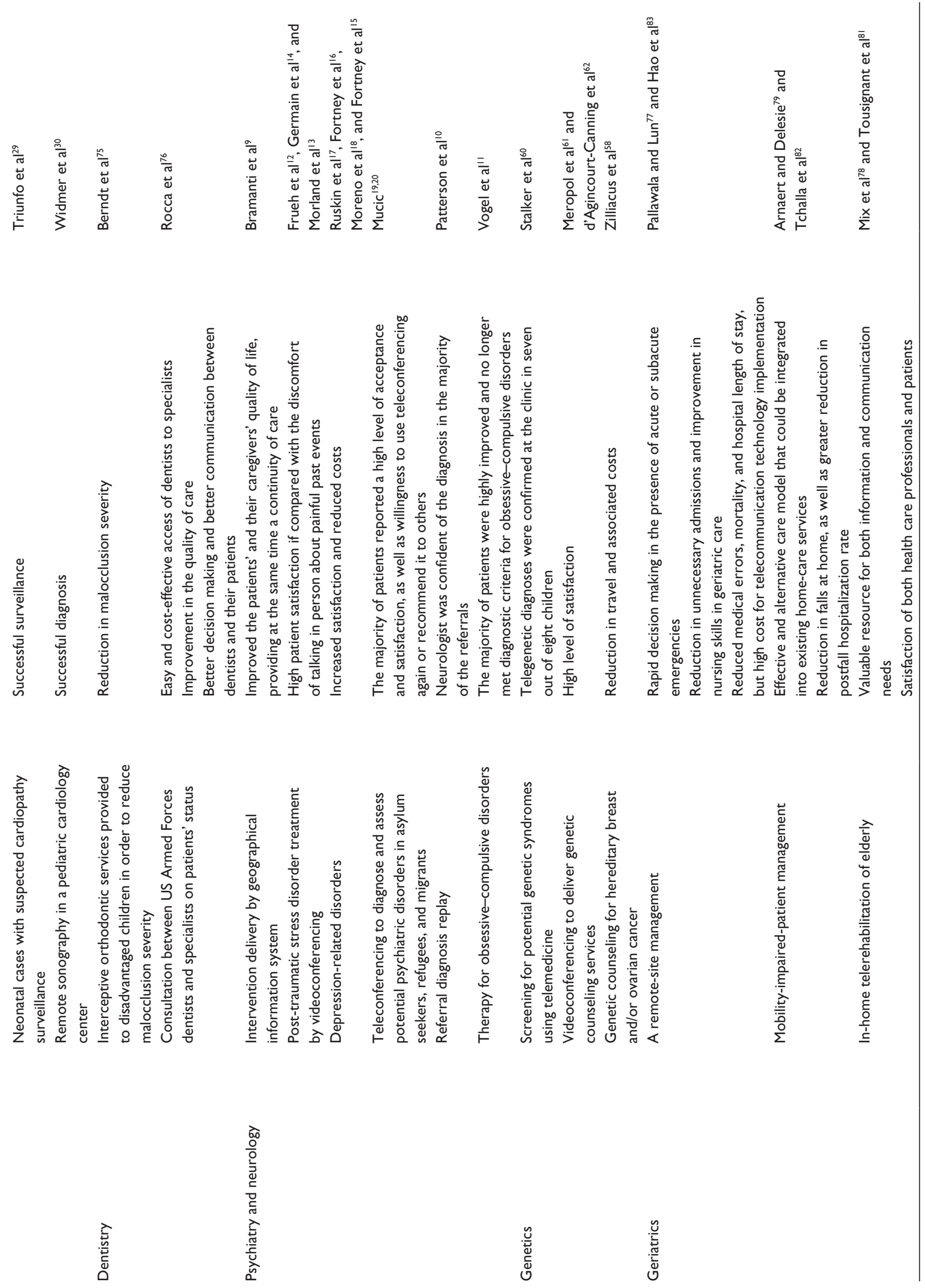
the field of ophthalmology was also showed by Kelly et al who described a quality improvement in terms of response delivery for referral to National Health Service patients with macular disorders from a community optometry setting (Royal Bolton Hospital, Bolton and Wallwork Opticians, Salford) in an urban area. ${ }^{50}$ In particular, 50 patients were monitored over 1 year using the telemedicine approach, and their responses were provided by hospital eye service-based ophthalmologists to the community optometrist or patient within the same day in 34 cases (68\%) and the next day in 14 patients (28\%). Eventually, 33 patients $(66 \%)$ required further face-to-face medical examination, whereas 17 (34\%) were managed in the community with a consequent cost improvement. A further study compared the telemedical approach with traditional surveillance with an eye care provider in order to perform diabetic retinopathy-screening examinations. ${ }^{51}$ Compared to the traditional surveillance group, telemedicine-treated patients were more likely to receive a diabetic retinopathy-screening examination within the first year of enrollment. Although 61 out of 296 patients within the telemedicine group required a further evaluation with an eye care provider, mainly due to poor-quality digital images, the introduction of nonmydriatic cameras reduced the number of participants who did not require a follow-up with an eye care provider. Further, telemedicine was also successfully used for diagnosis of treatment-warranted retinopathy of prematurity. ${ }^{52}$ After 5 years of screening of 511 infants, this report from Stanford University demonstrated 100\% sensitivity, $99.8 \%$ specificity, $93.8 \%$ positive predictive value, and $100 \%$ negative predictive value of telemedicine for detection of treatment-warranted retinopathy of prematurity screening in infants. Therefore, numerous studies have shown the value of telemedicine in the ophthalmology field by performing examinations far from the clinics.

\section{Genetics}

Telegenetics offers an alternative method to deliver genetic counseling services, and has been previously reviewed. ${ }^{53-57}$ A study showed that 12 women who had received genetic counseling for hereditary breast and/or ovarian cancer expressed their satisfaction with telegenetics in terms of reduced travel and associated costs. ${ }^{58}$ Recently, Scheuner et al conducted a web-based survey of Veterans Health Administration clinical leaders, which revealed that cancer genetic and neurogenetic consultations were the most common. The traditional model of multidisciplinary specialty clinics or coordinated services between geneticists and other providers proved the most efficient. On the contrary, telegenetic consultations showed some variability in terms of service organization, thus influencing the quality of care. ${ }^{59}$ In 2006 , a genetics counselor and a pediatrician performed a physical examination to screen for potential genetic syndromes in eight children via telemedicine at first and then face-to-face by a clinical geneticist. ${ }^{60}$ In seven children, telegenetic diagnoses were confirmed at the clinic. Moreover, none of the telegenetic diagnoses were deemed inaccurate. Therefore, these preliminary data suggest that telegenetics is a reliable tool to provide quicker confirmation of the absence of a particular genetic syndrome. A further study involving 31 adults examined the feasibility of home videoconferencing to provide cancer genetic education and risk information to subjects with possible hereditary colon, breast, or ovarian cancer syndromes. ${ }^{61}$ All participants stated that they would recommend Internet-based counseling to others, and also reported a high level of satisfaction. The delivery of a genetic counseling service has been evaluated by the BC Cancer Agency's Hereditary Cancer Program for British Columbia and Yukon residents. This agency assessed the acceptability and effectiveness of videoconferencing to deliver genetic counseling services to 64 patients living in rural and remote areas of British Columbia. ${ }^{62}$ At the end of the study, both patients' and counselors' surveys showed a favorable response to videoconference appointments, either in terms of costs or time saved. Telegenetic counseling was also compared to face-to-face consultations in terms of psychological approach to the diagnosis. ${ }^{63}$ A significant reduction in cancer-related anxiety levels and high satisfaction levels were reported, as well as a trend toward increased cancer genetic knowledge, thus indicating that telegenetic consultation could be considered as an alternative to face-to-face consultations. Therefore, telegenetic counseling for hereditary diseases is well suited to the exchange of medical information and medical records, considering the possibility that a hereditary cancer syndrome may be present, and reviewing risk-management strategies based on the patient's family cancer history.

\section{Pathology and microbiology}

Telepathology and telemicrobiology relate to the electronic transmission of images from one location to another with the aim of interpreting and formulating a diagnosis. In eastern Quebec, a successful telepathology project provided a uniform diagnostic telepathology service across a large geographic region with a low population density. ${ }^{64}$ This project provided surgeons and pathologists with frozen-section and secondopinion services across the whole region to limit unnecessary patient transfer. Frozen-section and tissue-smear preparations 
from 30 cases of brain tumors were digitized at $20 \times$ magnification and used for intraoperative telepathology without affecting the image quality. ${ }^{65}$ Recently, a pilot telepathology project between the Italian hospital Umberto Primo in Cairo and the Civico Hospital in Palermo was published. ${ }^{66}$ This project began in 2003 and has been extended until 2012, showing the usefulness of telepathology in consulting about difficult cases in a time- and cost-effective fashion. In summary, in the field of pathology, telemedicine is useful for achieving diagnosis through the travel of specimen digital images without the necessity of moving the patient. In this field, teleconsultation is cost-effective and reliable for rapid consultation on difficult pathological cases, especially in emerging countries.

As for microbiology, it has been recently combined with telemedicine in order to provide rapid on-time diagnosis of infectious diseases during missions ${ }^{67}$ For example, a camera and related software were installed in mission laboratories where teleparasitology was the most used application. The final result was the gaining of microbiology expertise in the area of the mission without the necessity of the physical presence of an expert.

\section{Oncology}

Hazin and Qaddoumi ${ }^{68}$ proposed that:

Teleoncology-oncology applications of medical telecommunications, including pathology, radiology, and other related disciplines have the potential to enhance access to and quality of clinical cancer care, and improve education and training.

In particular, at the 2010 American Telemedicine Association meeting, Doolittle et al showed a detailed summary of the costs associated with delivering cancer care by videoconferencing over a 10-year period at the University of Kansas Medical Center in Kansas City, Kansas. In 1995, 103 teleoncology visits resulted in a cost per visit of $\$ 812$; in 2000, \$410 for 121 visits; in 2003, \$401 for 219 visits; and in 2005, $\$ 251$ for 235 visits. ${ }^{69}$ While the number of teleconsultations has been rapidly increasing, these data clearly show that teleoncology has become less expensive throughout the years.

\section{Gastroenterology}

Telemedicine allows gastroenterologists to provide different forms of care to patients in remote locations. In 2011, in ten simulated cases with a range of swallowing difficulties, dysphagia was assessed simultaneously by a face-to-face speech pathologist and a telerehabilitation speech pathologist.
Simulated patients were individually examined by a clinical swallowing examination protocol, which was administered with the support of an assistant via an Internet-based videoconferencing telerehabilitation system. Excellent levels of agreement between the telerehabilitation speech pathologist and the face-to-face speech pathologist for all clinical swallowing examination parameters were observed. ${ }^{70}$ In another area of gastroenterology, endoscopic images of 2,084 patients were recorded and evaluated by 55 observers at different locations. ${ }^{71}$ This study showed adequate repeatability and intraobserver agreement of the assessments. These studies suggest that telemedicine can be as effective as face-to-face examination for swallowing disorder assessment and could be applied to other aspects of gastroenterology care.

\section{Dermatology}

Telecommunication technology has found application in the field of dermatology. In 2008, the US Army Medical Department allowed the use of a telemedicine system for health care providers in remote countries, including Iraq, Kuwait, and Afghanistan, for medical consultations. In a 36-month period, 2,337 consultations ( $66 \%$ for dermatology) were performed, with an average reply time of 5 hours from the receipt of teleconsultation until a recommendation was sent to the referring physician. ${ }^{72}$ More recently, in New Zealand, in a virtual lesion clinic, $88 \%$ of patients did not require any subsequent face-to-face clinic assessment to establish the diagnosis. In those patients seen in the virtual lesion clinic compared to face-to-face examination, the mean waiting time for first assessment was reduced from 114 days to 39 days and patients' costs was reduced by a third. ${ }^{73}$ Therefore, teledermatology reduces dermatology care-associated costs as well as patients' waiting time.

\section{Dentistry}

Teledentistry has been developing since 1994 to connect dental professionals over long distances. Furthermore, it is a useful and cost-effective instrument to connect specialists with rural or underserved populations. ${ }^{74}$ In the US, it was used to provide interceptive orthodontic services to disadvantaged children in order to reduce malocclusion severity. ${ }^{75}$ Total Dental Access, a teledentistry project within the Department of Defense, has been developed to allow dentists from the US Armed Forces to consult specialists on a patient's status. ${ }^{76}$ This tool provides dentists with easy and cost-effective access to specialists, resulting in an improvement in the quality of care, allowing better decision making and better communication between dentists and their patients. 


\section{Geriatrics}

Several studies have tested the applications of telecommunication technology in the field of geriatrics. A telegeriatric system, used to manage geriatric patients at a remote site, led to rapid decision making in the presence of acute or subacute emergencies, reducing unnecessary admissions and improving nursing skills in geriatric care. ${ }^{77}$ This study showed that telemedicine can speed up patients' management and also contribute to nurse professional development. The potential of modern telecommunication technology to improve the quality of life for elders with physical and mental impairments was proven during the telerehabilitation project TeleReha, which was conducted at the Berlin Geriatric Center on 13 mobility-impaired patients (mean age 72 years).${ }^{78}$ Results indicated that telecommunication devices were considered by participants as a valuable resource for their information and communication needs, and that the use of telecommunication was inversely related to physical mobility. Seven years later, in Belgium, 71 homebound elderly were admitted to videophone nursing care to measure changes in their functioning..$^{79}$ Based on multidimensional scaling algorithm evaluation, telecare resulted in an effective and alternative care model that could be integrated into existing home-care services. The effectiveness of home telemonitoring has been also addressed with the aim of reducing the combined outcomes of hospitalization and emergency department visits of elderly patients with mixed chronic disease. ${ }^{80}$ On the other hand, Tousignant et al scored the satisfaction of both patients and health care professionals with the technologies and services provided during in-home telerehabilitation after discharge from total-knee arthroplasty surgery. ${ }^{81}$ Forty-eight community-living elderly were recruited after receiving total-knee arthroplasty prior to discharge from acute care following surgery and randomly assigned to treatment arms (in-home telehealth assessment and face-to-face treatment). At the end of the intervention, participants' satisfaction was assessed for both groups using the Health Care Satisfaction Questionnaire. The satisfaction of the health care professionals with the technology during the telerehabilitation services was noted at the end of each treatment session using a technical-quality subjective appreciation questionnaire. Overall satisfaction and quality with the technological platform was observed. The need of a teleassistance service for the elderly prompted the development of a longitudinal prospective cohort study on 194 adults aged 65 years and over living at home with a high risk of developing functional impairments and multimorbidities (eg, falls at home).
These patients were followed by a light path coupled with a teleassistance service. ${ }^{82}$ The authors observed that $40.5 \%$ of the elderly fell at home, $30.9 \%$ in the exposed group and $50.0 \%$ in the unexposed group. The use of the light path coupled with teleassistance was significantly associated with a reduction in falls at home. Moreover, a greater reduction in the postfall hospitalization rate in the exposed group was observed. A recent article reported the innovative introduction of the tele-intensive care unit (tele-ICU), consisting of highly skilled staff trained in critical care and able to deliver timely quality care service to elderly patients admitted to ICUs in remote areas using highly advanced information-technology services. ${ }^{83}$ The clinical benefits of such a system improved patient outcomes and reduced medical errors, mortality, and hospital length of stay. On the other hand, the main disadvantage could be the high upfront cost involved in its implementation. Therefore, considering the burgeoning aging population, teleassistance for elderly people could be a valuable alternative to more expensive and time-consuming face-to-face care in terms of treatment accuracy.

\section{Discussion and conclusion}

This review outlines the use of telemedicine as an important cost-effective tool providing at least the same quality of medical care as face-to-face consultation in numerous medical fields. It allows rapid consultation among specialists, and erases geographic distance. Telemedicine opens new horizons for medical consultation, increases benefits for patients, and allows rapid exchange of information and techniques. Information and communication technology provides medical care to patients who have poor access to hospitals, and ensures continuity of care and optimal use of available health resources. For this reason, in terms of costs and benefits, private and public health institutions need such a network to optimize their resources. The use of telemedicine opens new perspectives for the growing number of patients seeking a medical second opinion for their pathology, ${ }^{84,85}$ since they can remotely access medical resources that would otherwise require enormous costs and time. The limitations of this review are the lack of a systematic or fully longitudinal approach. Telemedicine may represent a way to limit the "web Babel syndrome", ${ }^{84-86}$ avoiding the frustration and misunderstanding derived from accessing heterogeneous and misleading online medical information, and relying on experts who can provide a professional medical consultation and opinion. 


\section{Acknowledgment}

JCMM acknowledges CONACyT for membership.

\section{Disclosure}

The authors report no conflicts of interest in this work.

\section{References}

1. Statistics Netherlands VH. Research personal ICT-use: 2005; 2005.

2. Fox S, Jones S. The Social Life of Internet Users. Washington: Pew Internet and American Life Project; 2009.

3. Strehle EM, Shabde N. One hundred years of telemedicine: does this new technology have a place in paediatrics? Arch Dis Child. 2006;91(12):956-959.

4. Martinez AW, Phillips ST, Carrilho E, Thomas SW 3rd, Sindi H, Whitesides GM. Simple telemedicine for developing regions: camera phones and paper-based microfluidic devices for real-time, off-site diagnosis. Anal Chem. 2008;80(10):3699-3707.

5. Swendeman D, Rotheram-Borus MJ. Innovation in sexually transmitted disease and HIV prevention: internet and mobile phone delivery vehicles for global diffusion. Curr Opin Psychiatry. 2010;23(2):139-144.

6. Fraser HS, McGrath SJ. Information technology and telemedicine in sub-Saharan Africa. BMJ. 2000;321(7259):465-466.

7. Jefee Bahloul H, Mani N. International telepsychiatry: a review of what has been published. J Telemed Telecare. 2013;19(5):293-294.

8. Postel MG, de Haan HA, De Jong CA. E-therapy for mental health problems: a systematic review. Telemed J E Health. 2008;14(7):707-714.

9. Bramanti A, Bonanno L, Celona A, et al. GIS and spatial analysis for costs and services optimization in neurological telemedicine. Conf Proc IEEE Eng Med Biol Soc. 2010;2010:2204-2207.

10. Patterson V, Swinfen P, Swinfen R, Azzo E, Taha H, Wootton R. Supporting hospital doctors in the Middle East by email telemedicine: something the industrialized world can do to help. J Med Internet Res. 2007;9(4):e30.

11. Vogel PA, Launes G, Moen EM, et al. Videoconference- and cell phone-based cognitive-behavioral therapy of obsessive-compulsive disorder: a case series. J Anxiety Disord. 2012;26(1):158-164.

12. Frueh BC, Monnier J, Yim E, Grubaugh AL, Hamner MB, Knapp RG A randomized trial of telepsychiatry for post-traumatic stress disorder. $J$ Telemed Telecare. 2007;13(3):142-147.

13. Morland LA, Greene CJ, Rosen CS, et al. Telemedicine for anger management therapy in a rural population of combat veterans with posttraumatic stress disorder: a randomized noninferiority trial. J Clin Psychiatry. 2010;71(7):855-863.

14. Germain V, Marchand A, Bouchard S, Drouin MS, Guay S. Effectiveness of cognitive behavioural therapy administered by videoconference for posttraumatic stress disorder. Cogn Behav Ther. 2009;38(1):42-53.

15. Fortney JC, Pyne JM, Mouden SB, et al. Practice-based versus telemedicine-based collaborative care for depression in rural federally qualified health centers: a pragmatic randomized comparative effectiveness trial. Am J Psychiatry. 2013;170(4):414-425.

16. Fortney JC, Pyne JM, Edlund MJ, et al. A randomized trial of telemedicine-based collaborative care for depression. J Gen Intern Med. 2007;22(8):1086-1093.

17. Ruskin PE, Silver-Aylaian M, Kling MA, et al. Treatment outcomes in depression: comparison of remote treatment through telepsychiatry to in-person treatment. Am J Psychiatry. 2004;161(8):1471-1476.

18. Moreno FA, Chong J, Dumbauld J, Humke M, Byreddy S. Use of standard webcam and Internet equipment for telepsychiatry treatment of depression among underserved Hispanics. Psychiatr Serv. 2012; 63(12):1213-1217.

19. Mucic D. International telepsychiatry: a study of patient acceptability. $J$ Telemed Telecare. 2008;14(5):241-243.

20. Mucic D. Transcultural telepsychiatry and its impact on patient satisfaction. J Telemed Telecare. 2010;16(5):237-242.
21. Birati E, Roth A. Telecardiology. Isr Med Assoc J. 2011;13(8):498-503.

22. Bernocchi P, Scalvini S, Tridico C, et al. Healthcare continuity from hospital to territory in Lombardy: TELEMACO project. Am J Manag Care. 2012;18(3):e101-e108.

23. Sekar P, Vilvanathan V. Telecardiology: effective means of delivering cardiac care to rural children. Asian Cardiovasc Thorac Ann. 2007;15(4): 320-323.

24. Wister A, Loewen N, Kennedy-Symonds H, McGowan B, McCoy B, Singer J. One-year follow-up of a therapeutic lifestyle intervention targeting cardiovascular disease risk. CMAJ. 2007;177(8): 859-865.

25. Nolan RP, Liu S, Shoemaker JK, et al. Therapeutic benefit of internet-based lifestyle counselling for hypertension. Can J Cardiol. 2012;28(3):390-396.

26. McCrossan BA, Sands AJ, Kileen T, Cardwell CR, Casey FA. Fetal diagnosis of congenital heart disease by telemedicine. Arch Dis Child Fetal Neonatal Ed. 2011;96(6):F394-F397.

27. Dowie R, Mistry H, Young TA, et al. Telemedicine in pediatric and perinatal cardiology: economic evaluation of a service in English hospitals. Int J Technol Assess Health Care. 2007;23(1): 116-125.

28. Balk AH, Davidse W, Dommelen P, et al. Tele-guidance of chronic heart failure patients enhances knowledge about the disease. A multi-centre, randomised controlled study. Eur J Heart Fail. 2008; 10(11):1136-1142.

29. Triunfo R, Tumbarello R, Sulis A, et al. COTS technologies for telemedicine applications. Int J Comput Assist Radiol Surg. 2010;5(1):11-18.

30. Widmer S, Ghisla R, Ramelli GP, et al. Tele-echocardiography in paediatrics. Eur J Pediatr. 2003;162(4):271-275.

31. Mulholland HC, Casey F, Brown D, et al. Application of a low cost telemedicine link to the diagnosis of neonatal congenital heart defects by remote consultation. Heart. 1999;82(2):217-221.

32. Trippi JA, Lee KS, Kopp G, Nelson D, Kovacs R. Emergency echocardiography telemedicine: an efficient method to provide 24-hour consultative echocardiography. J Am Coll Cardiol. 1996;27(7): $1748-1752$.

33. Broekhuizen K, van Poppel MN, Koppes LL, Kindt I, Brug J, van Mechelen W. No significant improvement of cardiovascular disease risk indicators by a lifestyle intervention in people with familial hypercholesterolemia compared to usual care: results of a randomised controlled trial. BMC Res Notes. 2012;5:181.

34. Rogers FB, Ricci M, Caputo M, et al. The use of telemedicine for real-time video consultation between trauma center and community hospital in a rural setting improves early trauma care: preliminary results. J Trauma. 2001;51(6):1037-1041.

35. Link RE, Schulam PG, Kavoussi LR. Telesurgery. Remote monitoring and assistance during laparoscopy. Urol Clin North America. 2001; 28(1):177-188.

36. Park JW, Lee DH, Kim YW, Lee BH, Jo YH. Lapabot: a compact telesurgical robot system for minimally invasive surgery: part II. Telesurgery evaluation. Minim Invasive Ther Allied Technol. 2012; 21(3):195-200.

37. Abbou CC, Hoznek A, Salomon L, et al. [Remote laparoscopic radical prostatectomy carried out with a robot. Report of a case]. Prog Urol. 2000;10(4):520-523. French.

38. Rasswailer J, Safi KC, Subotic S, et al. Robotics and telesurgery--an update on their position in laparoscopic radica prostatetomy. Minim Invasive Ther Allied Technol. 2005;14(2):109-122.

39. Rassweiler J, Frede T, Seemann O, et al. Telepresence surgery: first experiences with laparoscopic radical prostatectomy. Minim Invasive Ther Allied Technol. 2001;10(6):261-270.

40. Luke PP, Girvan AR, Al Omar M, Beasley KA, Carson M. Laparoscopic robotic pyeloplasty using the Zeus Telesurgical System. Can J Urol. 2004;11(5):2396-2400.

41. Melvin WS, Dundon JM, Talamini M, Horgan S. Computer-enhanced robotic telesurgery minimizes esophageal perforation during Heller myotomy. Surgery. 2005;138(4):553-558; discussion 558-559. 
42. Nguan CY, Morady R, Wang C, et al. Robotic pyeloplasty using internet protocol and satellite network-based telesurgery. Int J Med Robot. 2008;4(1):10-14.

43. Rassweiler J, Frede T. [Geometry of laparoscopy, telesurgery, training and telementoring]. Urologe A. 2002;41(2):131-143. German.

44. Varkarakis IM, Rais-Bahrami S, Kavoussi LR, Stoianovici D. Robotic surgery and telesurgery in urology. Urology. 2005;65(5):840-846.

45. Janetschek G, Bartsch G, Kavoussi LR. Transcontinental interactive laparoscopic telesurgery between the United States and Europe. J Urol. 1998;160(4):1413.

46. Anvari M. Telesurgery: remote knowledge translation in clinical surgery. World J Surg. 2007;31(8):1545-1550.

47. Haidegger T, Sándor J, Benyó Z. Surgery in space: the future of robotic telesurgery. Surg Endosc. 2011;25(3):681-690.

48. Sterbis JR, Hanly EJ, Herman BC, et al. Transcontinental telesurgical nephrectomy using the da Vinci robot in a porcine model. Urology. 2008;71(5):971-973.

49. Ausayakhun S, Skalet AH, Jirawison C, et al. Accuracy and reliability of telemedicine for diagnosis of cytomegalovirus retinitis. Am J Ophthalmol. 2011;152(6):1053-1058.e1.

50. Kelly SP, Wallwork I, Haider D, Qureshi K. Teleophthalmology with optical coherence tomography imaging in community optometry. Evaluation of a quality improvement for macular patients. Clin Ophthalmol. 2011;5:1673-1678.

51. Mansberger SL, Gleitsmann K, Gardiner S, et al. Comparing the effectiveness of telemedicine and traditional surveillance in providing diabetic retinopathy screening examinations: a randomized controlled trial. Telemed J E Health. 2013;19(12):942-948.

52. Fijalkowski N, Zheng LL, Henderson MT, et al. Stanford University Network for Diagnosis of Retinopathy of Prematurity (SUNDROP): five years of screening with telemedicine. Ophthalmic Surg Lasers Imaging Retina. 2014;45(2):106-113.

53. Hopper B, Buckman M, Edwards M. Evaluation of satisfaction of parents with the use of videoconferencing for a pediatric genetic consultation. Twin Res Hum Genet. 2011;14(4):343-346.

54. McDonald E, Lamb A, Grillo B, Lucas L, Miesfeldt S. Acceptability of telemedicine and other cancer genetic counseling models of service delivery in geographically remote settings. J Genet Couns. 2014; 23(2):221-228.

55. Hilgart JS, Hayward JA, Coles B, Iredale R. Telegenetics: a systematic review of telemedicine in genetics services. Genet Med. 2012;14(9): 765-776.

56. Lea DH. A new world view of genetics service models. Online J Issues Nurs. 2000;5(3):5.

57. Abrams DJ, Geier MR. A comparison of patient satisfaction with telehealth and on-site consultations: a pilot study for prenatal genetic counseling. J Genet Couns. 2006;15(3):199-205.

58. Zilliacus EM, Meiser B, Lobb EA, Kirk J, Warwick L, Tucker K. Women's experience of telehealth cancer genetic counseling. J Genet Couns. 2010;19(5):463-472.

59. Scheuner MT, Marshall N, Lanto A, et al. Delivery of clinical genetic consultative services in the Veterans Health Administration. Genet Med. 2014;16(8):609-619.

60. Stalker HJ, Wilson R, McCune H, Gonzalez J, Moffett M, Zori RT. Telegenetic medicine: improved access to services in an underserved area. J Telemed Telecare. 2006;12(4):182-185.

61. Meropol NJ, Daly MB, Vig HS, et al. Delivery of Internet-based cancer genetic counselling services to patients' homes: a feasibility study. J Telemed Telecare. 2011;17(1):36-40.

62. d'Agincourt-Canning L, McGillivray B, Panabaker K, et al. Evaluation of genetic counseling for hereditary cancer by videoconference in British Columbia. BCMJ. 2008;50(10):554-559.

63. Coelho JJ, Arnold A, Nayler J, Tischkowitz M, MacKay J. An assessment of the efficacy of cancer genetic counselling using real-time videoconferencing technology (telemedicine) compared to face-to-face consultations. Eur J Cancer. 2005;41(15):2257-2261.
64. Têtu B, Fortin JP, Gagnon MP, Louahlia S. The challenges of implementing a "patient-oriented" telepathology network; the Eastern Québec telepathology project experience. Anal Cell Pathol (Amst). 2012;35(1):11-18.

65. Gould PV, Saikali S. A comparison of digitized frozen section and smear preparations for intraoperative neurotelepathology. Anal Cell Pathol (Amst). 2012;35(2):85-91.

66. Ayad E, Yagi Y. Virtual microscopy beyond the pyramids, applications of WSI in Cairo University for E-education and telepathology. Anal Cell Pathol (Amst). 2012;35(2):93-95.

67. Scheid PL. [Use of telemedicine within the diagnosis of parasites and viruses]. Wien Klin Wochenschr. 2012;124 Suppl 3:10-13. German.

68. Hazin R, Qaddoumi I. Teleoncology: current and future applications for improving cancer care globally. Lancet Oncol. 2010;11(2): 204-210.

69. Doolittle GC, Spaulding AO, Williams AR. The decreasing cost of telemedicine and telehealth. Telemed J E Health. 2011;17(9): 671-675.

70. Sharma S, Ward EC, Burns C, Theodoros D, Russell T. Assessing swallowing disorders online: a pilot telerehabilitation study. Telemed $J$ E Health. 2011;17(9):688-695.

71. de Lange T, Svensen AM, Larsen S, Aabakken L. The functionality and reliability of an Internet interface for assessments of endoscopic still images and video clips: distributed research in gastroenterology. Gastrointest Endosc. 2006;63(3):445-452.

72. McManus J, Salinas J, Morton M, Lappan C, Poropatich R. Teleconsultation program for deployed soldiers and healthcare professionals in remote and austere environments. Prehosp Disaster Med. 2008;23(3):210-216; discussion 217.

73. Lim D, Oakley AM, Rademaker M. Better, sooner, more convenient: a successful teledermoscopy service. Australas J Dermatol. 2012;53(1):22-25.

74. Sanchez Dils E, Lefebvre C, Abeyta K. Teledentistry in the United States: a new horizon of dental care. Int J Dent Hyg. 2004;2(4): $161-164$.

75. Berndt J, Leone P, King G. Using teledentistry to provide interceptive orthodontic services to disadvantaged children. Am J Orthod Dentofacial Orthop. 2008;134(5):700-706.

76. Rocca MA, Kudryk VL, Pajak JC, Morris T. The evolution of a teledentistry system within the Department of Defense. Proc AMIA Symp. 1999:921-924.

77. Pallawala PM, Lun KC. EMR based telegeriatric system. Int $J$ Med Inform. 2001;61(2-3):229-234.

78. Mix S, Borchelt M, Nieczaj R, Trilhof G, Steinhagen-Thiessen E. [Telematics in geriatrics - potentials, problems and application experiences]. Z Gerontol Geriatr. 2000;33(3):195-204. German.

79. Arnaert A, Delesie L. Effectiveness of video-telephone nursing care for the homebound elderly. Can J Nurs Res. 2007;39(1): $20-36$.

80. Takahashi PY, Hanson GJ, Pecina JL, et al. A randomized controlled trial of telemonitoring in older adults with multiple chronic conditions: the Tele-ERA study. BMC Health Serv Res. 2010;10:255.

81. Tousignant M, Boissy P, Moffet H, et al. Patients' satisfaction of healthcare services and perception with in-home telerehabilitation and physiotherapists' satisfaction toward technology for post-knee arthroplasty: an embedded study in a randomized trial. Telemed $J$ E Health. 2011;17(5):376-382.

82. Tchalla AE, Lachal F, Cardinaud N, et al. Efficacy of simple home-based technologies combined with a monitoring assistive center in decreasing falls in a frail elderly population (results of the Esoppe study). Arch Gerontol Geriatr. 2012;55(3):683-689.

83. Hao JF, Cui HM, Han JM, Bai JX, Song X, Cao N. Tele-ICU: the way forward in geriatric care? Aging Clin Exp Res. Epub 2014, May 7.

84. Palmieri B, Iannitti T. The Web Babel syndrome. Patient Educ Couns. 2011;85(2):331-333. 
85. Palmieri B, Iannitti T, Capone S, Fistetto G, Arisi E. [Second opinion clinic: is the Web Babel Syndrome treatable?]. Clin Ter. 2011;162(6):575-583. Italian.
86. Palmieri B, Capone S, Fistetto G. [Second opinion consultation: is Babel-web syndrome curable?]. Recenti Prog Med. 2011;102(1):43. Italian.

\section{Publish your work in this journal}

Patient Preference and Adherence is an international, peer-reviewed, open access journal that focuses on the growing importance of patient preference and adherence throughout the therapeutic continuum. Patient satisfaction, acceptability, quality of life, compliance, persistence and their role in developing new therapeutic modalities and compounds to optimize clinical outcomes for existing disease states are major areas of interest for the journal. This journal has been accepted for indexing on PubMed Central The manuscript management system is completely online and includes a very quick and fair peer-review system, which is all easy to use. Visit http://www. dovepress.com/testimonials.php to read real quotes from published authors.

\footnotetext{
Submit your manuscript here: http://www.dovepress.com/patient-preference-and-adherence-journal
} 